\title{
Mental health literacy among vocational rehabilitation professionals and their perception of employers in the return-to-work process
}

\author{
Susann Porter ${ }^{\mathrm{a}, *}$, Annika Lexén ${ }^{\mathrm{a}, \mathrm{b}}$ and Ulrika Bejerholm ${ }^{\mathrm{a}}$ \\ ${ }^{a}$ Department of Health Sciences/Mental Health, Activity and Participation, Medical Faculty, \\ Lund University, Lund, Sweden \\ ${ }^{\mathrm{b}}$ Department of Health Sciences/Mental Health and Mental Health Services Research, Medical Faculty, \\ Lund University, Lund, Sweden
}

Revised/Accepted August 2018

\begin{abstract}
.
BACKGROUND: Individuals with mental health problems often need support from vocational rehabilitation professionals in their return-to-work (RTW) process. Research has shown that this support can be deficient, with vocational rehabilitation professionals lacking relevant knowledge and an underlying belief in the individual's ability to resume a working life. More understanding is therefore needed of professionals' mental health literacy and their perception of and influence on employer roles in the RTW process.

OBJECTIVE: To explore the mental health literacy of Swedish vocational rehabilitation professionals and their perception of employers in the RTW process.

METHOD: Qualitative grounded theory study which included 22 interviews of vocational rehabilitation professionals working with individuals with mental health problems in their RTW process.

RESULTS: Three categories emerged: holding a position of power in the RTW process, viewing and believing in individuals' work ability plays a central role, and recognizing the employer's role as a key factor for realizing employment.

CONCLUSION: Increasing the mental health literacy of vocational rehabilitation professionals is crucial since they have a decisive role with both clients and employers in the RTW process.
\end{abstract}

Keywords: Vocational rehabilitation, return-to-work, mental health problems, employment support

\section{Introduction}

Mental health problems are a worldwide concern that affect both society and the individual (Chisholm et al., 2016; Marcus, Yasamy, van Ommeren, Chisholm, \& Saxena, 2012). In Sweden, mental

\footnotetext{
*Address for correspondence: Susann Porter, Department of Health Sciences/Mental Health, Activity and Participation, Lund University, P.O. Box 157, SE-221 00 Lund, Sweden. Tel.: +46 702 9835 44; E-mail: susann.porter@med.lu.se.
}

health problems are the primary reason for exclusion from the labour market among the working age population (OECD, 2013). The return-to-work (RTW) process refers to the process that the individual follows on the way to employment, and the employment outcome (Ekberg, Eklund, \& Hensing, 2015). To have hope, power, and be supported through a personalized approach are essential in the RTW process for people with mental health problems (Porter \& Bejerholm, 2018; Porter, Lexén, Johanson, \& Bejerholm, 
2018). Employment itself is shown to benefit individuals with mental health problems by contributing to their recovery (Bejerholm \& Areberg, 2014; Slade, 2010). Their feelings of autonomy and social status increase while their depression and anxiety symptoms decrease (Joyce et al., 2016).

In Sweden, individuals in the RTW process encounter diverse groups of vocational rehabilitation professionals (labelled as 'professionals' for the remainder of this article) who have different perspectives and regulations to follow (Bejerholm, Areberg, Hofgren, Sandlund, \& Rinaldi, 2015; Burstrom, Nylen, Clayton, \& Whitehead, 2011). However, the mental health literacy of these professionals is often lacking, and this has consequences on RTW support, which may become deficient, delayed, or none existent (De Vries, Hees, Koeter, Lagerveld, \& Schene, 2014; Lexén, Emmelin, \& Bejerholm, 2016; Porter, Lexén, Johanson, \& Bejerholm, 2018). Mental health literacy is defined in this study as the beliefs and knowledge of mental health problems which consequently affect the prevention, recognition and management of these mental health problems. The definition includes the ability to distinguish and discern various types of mental health problems, the knowledge of where and how to pursue information regarding risk factors, and strategies concerning interventions and professional beliefs and attitudes that impact a person's capability to recognise mental illness and seek suitable support (Jorm, Korten, Jacomb, Christensen, Rodgers, \& Pollitt, 1997).

It is important that individuals with mental health problems are provided with opportunities to gain, regain, and sustain employment. Exploration of professionals' mental health literacy is needed to understand and improve RTW support, and thus bridge the knowledge and service gap between the Mental Health Service and employment.

In this study, we use the concept of traditional vocational rehabilitation (TVR) when referring to the standard RTW process for individuals with mental health problems in Sweden (SOU, 2011). TVR includes various actors who are responsible for performing different interventions (Ekberg, 2009; Ståhl, Svensson, \& Ekberg, 2011). TVR is part of the social benefit and unemployment security system that includes the rehabilitation professionals in the Medical Health Service (MHS), the Occupational Health Service (OHS), primary care (PC), Public Employment Services (PES), and the Social Insurance Agency (SIA) (SOU, 2011). Complementary actors (CA) procured by PES and employment specialists working in accordance to the individual placement and support (IPS) approach (Bejerholm et al., 2015) are also included. PES works with clients who are outside the labour market due to mental health problems and those who are employed but need to change jobs.

The primary goal of these services is to support clinical recovery in a medical setting (Davidson, O'Connell, Tondora, Lawless, \& Evans, 2005) and to gradually increase work ability through vocational training and internships (Burstrom, Nylen, Clayton, \& Whitehead, 2011). A meta-review by Joyce et al. (2016) addressed the service and knowledge gap in TVR that exists between the Mental Health Service and other RTW services. These gaps are likely to disrupt the RTW process and prolong the sickleave period (Joyce et al., 2016). Recent research conducted in response to these gaps demonstrated that person-centred and enabling RTW support with professional and employer collaboration, leads to better RTW outcomes (Bejerholm, Larsson, \& Johanson, 2017; Lexén, Emmelin, \& Bejerholm, 2016; Reme, Grasdal, Løvvik, Lie, \& Øverland, 2015), decreased depression, and increased empowerment (Porter \& Bejerholm, 2018). This enabling support provides hope and power (Porter, Lexén, Johanson, \& Bejerholm 2018), and enhances development of individual self-efficacy, coping strategies and behaviours that are relevant for becoming employed (Johanson, Markstrom, \& Bejerholm, 2017; Topor \& Ljungberg, 2016). The IPS approach is experienced as distinctly different from TVR because individuals receive support adapted to their individual needs (Porter, Lexén, Johanson, \& Bejerholm, 2018). Employers also experience person-centred RTW support as decisive for employing individuals with mental health problems (Lexén, Emmelin, \& Bejerholm, 2016), and returning individuals to employment by means of personcentred support is cost effective, especially since individuals gain employment more frequently (Saha, Bejerholm, Gerdtham, \& Jarl, 2018). In contrast, disintegrated RTW support, where different professional performs their individual assessments as regulated by their organizations, has been shown to lead to less successful RTW outcomes (Modini et al., 2016).

Besides the professionals' roles in the RTW process, employers have a decisive role for a successful RTW process (Lexén, Emmelin, \& Bejerholm, 2016). Research has demonstrated that employer's knowl- 
edge regarding mental health problems is limited and deficient (Kirsh et al., 2009). A systematic review revealed that employers rate persons with mental health problems as less employable than persons with physical disabilities (Alonso et al., 2009; Brohan et al., 2012). As a result of this mindset, employers often rely on the support of professionals when hiring or providing RTW support to individuals with mental health problems (Lexén, Emmelin, \& Bejerholm, 2016). Previous research shows that negative attitudes in the workplace towards those with mental health problems were associated with scant support and fear of being discriminated, if mental health problems were disclosed (Moll, 2014). Nevertheless, when employers possess previous experience of employees with mental health problems, the negative concerns in the hiring process decrease (Brohan et al., 2012; Ju, Roberts, \& Zhang, 2013; Lexén, Emmelin, \& Bejerholm, 2016).

In summary, the chances of a successful RTW process may improve when professionals believe that the individuals are capable of working (Porter \& Bejerholm, 2018; Slade, 2010; Williams, Fossey, Corbiere, Paluch, \& Harvey, 2016). Yet research shows that this belief can be insufficiently convincing, and professionals may lack understanding, empathy, and confidence that an individual has the potential to work. This presents significant barriers for a successful outcome (Bertilsson, Love, Ahlborg, \& Hensing, 2015; Porter, Lexén, Johanson, \& Bejerholm, 2018). Employers rely on the support from professionals during the hiring and RTW process (Lexén, Emmelin, \& Bejerholm, 2016). Therefore, professionals play a key role in the RTW process, including contacting and collaborating with employers. The overall aim of this study was to explore vocational rehabilitation professional mental health literacy in the RTW process, including their perception of employers. The specific aims were to:

- Develop an understanding of professional mental health literacy regarding individuals with mental health problems in the RTW process.

- Develop an understanding of professional perception of employers in the RTW process.

\section{Methods}

Grounded theory was applied to guide the process of data collection and analysis (Charmaz, 2014, 2017). This method was chosen to create a concep-
Table 1

Abbreviations of Swedish authorities, organizations, and professionals included in this study $(n=7)$

\begin{tabular}{ll}
\hline CA & Complementary actor \\
IPS & Individual placement and support \\
MHS & Medical Health Service \\
OHS & Occupational Health Service \\
PC & Primary care \\
PES & Public Employment Service \\
SIA & Social Insurance Agency \\
\hline
\end{tabular}

Table 2

Socio-demographic characteristics of vocational rehabilitation professional study participants $(\mathrm{N}=22)$

\begin{tabular}{lc}
\hline Characteristics & $n$ \\
Sex & $18 / 4$ \\
$\quad$ Female/male & \\
Age in years & $47.1(31-66)$ \\
$\quad$ Mean (range) & \\
Education level in years & 3 \\
$\quad$ Upper secondary $>16$ & 19 \\
$\quad$ University/college $<18$ & \\
Work experience in years & $19.9(3-38)$ \\
$\quad$ Mean (range) & \\
Vocational rehabilitation in years & $15.7(3-23)$ \\
$\quad$ Mean (range) & \\
Type of authority/organization & 2 \\
Complementary actors & 2 \\
$\quad$ Individual placement and support & 2 \\
Mental Health Service & 3 \\
Occupational Health Service & 3 \\
Primary care & 4 \\
Public Unemployment Service & 6 \\
Social Insurance Agency & \\
\hline
\end{tabular}

tual model that could help to understand the RTW process as viewed from the perspective of professionals as previous research in this field is limited.

\subsection{Participants}

Eligible participants were professionals working within: CA, IPS, MHS, OHS, PC, PES, and SIA (Table 1). They worked in different authorities and organizations providing RTW support for individuals with mental health problems and had experience of contact with employers in the RTW process. The aim was to include women and men from the private and public sectors. The recruitment area was the county of Scania in southern Sweden.

A total of 22 individuals fulfilled the inclusion criteria and were asked to participate in the study. These individuals consisted of 18 women and 4 men with a mean age of 47 years (range 31-66). No individuals declined participation. Further characteristics are shown in Table 2. 


\subsubsection{Data collection and analysis}

Reports of interest in study participation were forwarded to the research team from a contact person in each recruitment authority/organization. Prospective participants were then contacted by email or telephone. They were provided with information about the study and asked if they were willing to meet for an interview. At the interview, additional study information was given verbally and in written form. All invited professionals gave their informed consent to participate. Interviews lasted between 30 to 90 minutes and were performed at the participant's workplace. Interviews were digitally recorded with consent of the participants.

The interview guide was developed by the research team and focused on questions exploring experiences related to mental health problems and the RTW process. Two pilot interviews were conducted, and only minor revisions were made. The interviews started with introductory questions during which the participants were invited to describe themselves and their motivation for working in this field. Other questions asked were: What is your view of people with mental health problems and their ability to work? What experiences do you have of meeting employers as part of the RTW process? Could you tell (me) about a situation of contact with an employer that you remember as being positive/negative? If other issues related to the study aims were brought up, these were noted and followed-up. The interviews were transcribed verbatim and analysed using incident-by-incident initial coding (Charmaz, 2014). More specific and modified question areas were gradually added, such as personal skills and experiences of mental health problems, attitudes and support strategies, and experiences of employer support needs. The procedure of feeding initial results back into the data collection process is essential in grounded theory (Charmaz, 2014). Along with the development of new question areas theoretical sampling was used. This entailed inclusion of professionals of different ages and genders, from different authorities and organizations, and with varying work experience that the authors believed could contribute to the emerging analysis. Data collection ended when no further categories could be found, and no new theoretical insights occurred in relation to the already emerged categories.

When the data collection phase concluded, focused coding, was the next step in the analysis process, i.e., the most frequent initial codes were used to categorise the data. These categories were then related and compared to each other in a process called axial coding.
In the last step, theoretical coding, the relationships between categories were defined. During the analysis process a strong category emerged that indicated the overall interpretation of the results. Throughout the data collection and analysis process the authors used memo-writing to reflect on and justify codes, categories and their relationships. This approach also enabled the researchers to recall earlier thoughts during the analysis process. Negative cases, i.e., data that displayed sharp contrast to the main result, were also included (Charmaz, 2014). All authors performed all steps of the analysis. Open Code 4.01 software was used throughout the data analysis process.

\subsection{Ethical considerations}

This study was conducted in agreement with the established ethical guidelines of the Declaration of Helsinki. Written information concerning the purpose of the study and a consent form was emailed to potential participants. Before interviews commenced, the participants gave written informed consent. Confidentiality and the right to terminate participation without giving a cause were guaranteed. The Regional Ethical Board in Lund, Sweden (Dnr 2015/90) approved the study.

\section{Results}

Three main categories emerged related to the study aims of which the strongest was the first: holding a position of power in the $R T W$ process, viewing and believing in individuals' work ability plays a central role, and recognizing the employer's role as a key factor for realizing employment. Holding a position of power in the RTW process encompassed the power professionals possessed in their diverse roles and the regulations framing that role, which were dependent on the authority or organization they represented. Their own knowledge, how they collaborated with other professionals, and how these aspects combined is a driving power in the RTW process. Viewing and believing in individuals' work ability plays a central role reflected the professional's personal views and beliefs regarding clients' ability to work, and their view of disclosure and stigma in relation to work and individuals with mental health problems. The third category, recognizing the employer's role as a key factor for realizing employment, considered the professional's perception of the employer's role since employer behaviours, knowledge and need of 
financials benefits had consequences for the client's opportunity to RTW. The categories and the respective sub-categories are shown in Table 3.

When referring to individuals with mental health problems, the terms clients, individuals and patients are used since professionals use these terms (depending on their workplace). Wage subsidies are defined as the various means through which the employer can receive financial compensation when employing a person with disabilities, including mental health problems. The compensation often decreases as the employee regains work ability as determined by regular assessments. In this article, no distinctions are made between the different benefits available. The type of benefit depends on the specific authority that pays the compensation and the purpose of the benefit. Notably, the employees receive their salary from the employer regardless of the underlying reason for the benefit provided to the employer.

\subsection{Holding a position of power in the RTW process}

Holding a position of power emerged as a strong category that reflects the significant position professionals hold toward the individual with mental health problems in their RTW process. The power originates from their professional role within the different authorities and organizations in the Swedish RTW process. Following regulations is the part of that professional role that impacted their use of knowledge and collaboration with other professionals. The variation in relation to power was illustrated in the support they delivered to clients/patients and employers.

\subsubsection{Diverse power roles in the RTW process}

Overall, professionals perceive themselves as having diverse professional roles in the RTW process. The roles were dependent on their profession and the regulations that framed their role. The different RTW authorities/organizations are regulated by political decisions. The professionals followed the assignments given to them, which largely focused on the individual's functional limitations.

The professional's role was articulated as supporting the individual in different ways, e.g. to be open to what the client wanted (CA, IPS, MHS, OHS, SIA, PC, PES), to make a proper job-person match (CA, IPS, PES), and to have a holistic perspective (CA, IPS, PC). They also described their roles as providing support to the employer, e.g. workplace accommodations, providing advice when and if needed (CA, IPS, OHS). Professionals who worked mainly with unemployed clients described the importance of networking with potential employers (CA, IPS, PES). For example, employment specialists (IPS) described their role as seeking out and having a close collaboration with potential employers and supporting employers while hiring clients with mental health problems. They also continued to provide needed support to the client and employer once employment was secured. Handling officers at PES described more limited opportunities to support the client and employers. In addition, SIA handling officers held contradictory views, describing their role as neither to support the employer nor link employers and employees (clients). Instead, handling officers supported their clients in engaging with the employers. One handling officer at SIA explained her role in relation to employers:

"It's more that I investigate, [and] simply push them. But I can't say I support them ... laugh... if I' $m$ honest, that isn't what I' $m$ doing."

Roles were diverse and occasionally contradictory among the various professionals involved in the RTW process. As mentioned, the power professionals hold derives from their role and the regulations set by their authority or organization.

Table 3

Professional mental health literacy influences the return-to-work (RTW) process

\begin{tabular}{ll}
\hline Categories & Sub-Categories \\
\hline $\begin{array}{l}\text { Holding a position of power in the RTW } \\
\text { process }\end{array}$ & $\begin{array}{l}\text { Diverse power roles in the RTW process } \\
\text { Deficient knowledge in combination with power is a barrier } \\
\text { Lack of collaboration causing time and service gaps }\end{array}$ \\
\hline $\begin{array}{l}\text { Viewing and believing in individuals' work } \\
\text { ability plays a central role }\end{array}$ & $\begin{array}{l}\text { Varying views of work for individuals with mental health problems } \\
\text { View of disclosure as both a positive and negative action }\end{array}$ \\
\hline $\begin{array}{l}\text { Recognizing employer's role as a key factor } \\
\text { for realizing employment }\end{array}$ & Employers as both barriers and enablers \\
& Employers in need of knowledge and support \\
& Financial situation impacts employer actions \\
\hline
\end{tabular}




\subsubsection{Deficient knowledge in combination with power is a barrier}

This sub-category concerns the professional's personal need of knowledge and support, and how deficient knowledge in combination with power can act as a barrier in the RTW of persons with mental illness. This was exemplified mainly by SIA professionals. Handling officers at SIA were clear that they were not medically trained and needed more knowledge and support from their own specialists, e.g. medical doctors, during contact with their clients. A stated requirement from SIA handling officers was to gain more knowledge about their own regulatory system as this could cause uncertainties, and they desired more knowledge regarding contact with employers. Professionals from other organizations held similar opinions about SIA. They (MHS, OHS) expressed that SIA professionals lacked knowledge regarding mental health problems and held negative attitudes towards individuals with mental health problems. Younger SIA handling officers were also sometimes perceived to be lacking compassion and viewing mental health problems as an excuse for laziness. SIA was perceived to be putting strain on clients' RTW process (OHS). MHS doctors also had negative perceptions of SIA and thought they were the biggest obstacle in the RTW process. They saw SIA handling officers as poorly skilled with very limited knowledge of mental health problems.

"It's a bad sign for a society that we allow an authority to have such poorly educated staff."

Handling officers at both PES and SIA expressed a need for mentoring in their role since it could be challenging at times. Nonetheless, SIA was not the only authority that was perceived as lacking knowledge. PC medical doctors were also seen as having deficient knowledge of mental health problems (OHS, SIA). In conclusion, professional lack of knowledge could act as a negative power, causing frustration among other professionals and resulting in a less effective RTW process.

\subsubsection{Lack of collaboration causing time and service gaps}

The collective view was that collaboration is essential between professionals and authorities or organizations. Deficient collaboration could cause service and time gaps and be a negative influence in the RTW process. Conversely, effective collaboration was regarded as a positive force. As an OHS professional explained:
"The work is so fun and easy and good for everyone, [but] mainly for the clients when we have good teamwork."

Even though collaboration was regarded as important, most professionals expressed that it was lacking between different actors in the RTW process. The OHS professionals desired improved collaboration between the MHS and employers in order to create a better understanding of employee mental health problems. SIA saw a problem with lack of collaboration manifested as waiting time for the individual to see the specialist MHS doctors. The consequence of long waits was to see a PC doctor with less competence in mental health problems instead (SIA). PC professionals felt that patients could be overlooked as a consequence of a lack of collaboration between PES and SIA, e.g., the patient was too ill for PES and too well for SIA. One OHS professional explained the way different actors worked:

"We all want the same things but do things differently."

Another cause of the lack of collaboration concerned failing to attend joint status meetings. The SIA handling officers described responsibility for these meetings and for contacting clients and other parties when they believed it was time to discuss RTW progress and further planning. However, even though SIA handling officers called for the status meetings, they often failed to attend themselves (MHS, PC). Their absence was explained by the heavy workload and frequent turnover of handling officers (MHS). Handing officers did not view their attendance as sufficiently important, and this meant that meetings could be held without them being present (PC). The cause for the lack of collaboration and time gaps in the RTW process was attributed to the turnover of SIA handling officers (MHS, PC). SIA handling officers concluded that there was frequent inertia in coordination between the diverse RTW actors, and this made the process slower than desired and a time, and service gap became evident. A team approach, with support organized as a person-centred approach around the individual that focused on a patient's abilities to work were perceived as influencing how patients viewed themselves as capable and working individuals (MHS). Overall this sub-category indicates that professionals lack of collaboration has a negative impact on the RTW process. 


\subsection{Viewing and believing in individuals' work ability plays a central role}

This category represents professionals' views and beliefs regarding their clients' ability to work and forms a central part of the understanding of mental health literacy among professionals. The professionals were ambivalent regarding the benefits of disclosing mental health problems since disclosure could be helpful and benefit the individual and be disadvantageous if the employer held negative views and beliefs about employees or jobseekers with mental health problems. The professionals observed that employers could have stigmatizing attitudes; however, these stigmatizing views and beliefs were also recognised to be present among professionals, the individuals suffering from mental health problems, and in society at large.

\subsubsection{Varying views of work for individuals with mental health problems}

This sub-category examined the professionals' personal views and beliefs of mental health problems in relation to work and their impact on the individual's RTW. The most common opinion was that individuals with mental health problems could work. A distinction was observed; professionals could mean work as employment with or without wage-subsidies for the employer.

Employment with wage-subsidies was viewed by most professionals as a way to enter back into the labour market after sick-leave (CA, IPS, PES, SIA), and was seen as temporary and needed for varying periods until the employee's work ability had improved (CA, IPS, MHS, OHS, PC, PES, SIA). A more pessimistic view was also expressed by CA professionals, who stated that employment without a wage-subsidy did not exist for individuals with mental health problems. Employment specialists (IPS) pointed out the importance to represent and empower the client as needed, and to address when subsidies and internship placement were not necessary.

According to PES handling officers, an individual did not need to be symptom-free prior to starting work because employers are compensated with wage-subsides for functional limitations. The SIA professionals explained that very few individuals lacked all work ability and that most people want to work. Sometimes, the individual was perceived as not attempting to get well and return to work, especially when work was the reason for sick-leave. This view was confirmed by PC medical doctors who described conflict and bullying at work being the leading reasons for current mental health problems and sick-leave.

Professionals mentioned the importance of matching the individual to the right employer and social work environment to facilitate employment (CA, IPS, MHS, PES, SIA). The work tasks were not viewed as the primary concern as the social environment could be more central (CA, PES). However, the employment specialists (IPS) focused on the work tasks. To develop sustainable employment, emphasis was placed on matching the individual's abilities and skills with the production needs of the company (IPS).

\subsubsection{View of disclosure as both a positive and negative action}

Professionals were ambivalent in their views of whether clients should disclose their mental health problems to employers and advocated for different degrees of openness. Some believed that total openness was the best approach (OHS, PES, SIA) while others were more cautious and put emphasis on the client's skills and abilities to handle work tasks. Professional opinions on the best approach in short- and long-term perspectives also varied (IPS). However, disclosure was consistently agreed to be the individual's choice. Employment specialists (IPS) expressed flexibility on whether to disclose to employers. The decision depended on whether the mental health problems affected the individual's functional limitations in relation to the work task and context. If no limitations were identified, disclosure would not be a concern. Parallels were drawn with how healthy individuals would act when meeting a potential employer:

"If, say, you or I are looking for a job... we will not tell all about our dark sides or stuff right away when we are trying to get a job."

The PC professionals expressed a positive disposition toward disclosure to employers but also stated that a diagnosis could limit the individual since prejudices are common. When hiring a person with a wage-subsidy, PES professionals stated that it is essential to disclose the diagnosis to allow the employer to understand the employee's functional limitations and reason for the wage-subsidy. OHS professionals pointed out that the employer needs to be informed because they are paying for services, but that the degree of disclosure was the individual's choice. 


\subsubsection{Stigma is a part of the view of work ability}

Overall, stigma concerning mental health problems was viewed as leading to fear, distrust or prejudice, and influences professionals' view of the work ability of their clients with mental health problems.

Individuals with mental health problems may also perceive themselves as less capable, i.e., having selfstigma that manifests in low self-belief in their work ability and being overly self-critical (CA, MHS, PC). The medical sick-leave certificate was described as a concern because it emphasized the illness. This in itself, could be stigmatizing for the individual (MHS, PES). Society was generally also observed as stigmatizing individuals with mental health problems (OHS, PC, SIA), and women are stigmatized more than men (SIA, PC). Furthermore, society was described as tough, lacking tolerance, and where people with mental health problems risk exclusion (MHS, PC, PES, SIA). A related finding was that stigma exists within the professionals' authorities. SIA and PES handling officers shared a fear and insecurity around individuals who show severe signs of mental health problems. In the case of PES, this fear had led to professionals not seeing clients alone, and if they felt threatened, they could use a staff panic room. Professionals in both SIA and PES stated that stigma existed among their own colleagues and that clients were disrespected because of their mental health problems. This was explained by a SIA handling officer who referred to general societal prejudice:

"Because we are like most people, it's unfortunately so."

\subsection{Recognizing employer's role as a key factor for realizing employment}

Employers were described by RTW professionals as both a barrier and a necessary enabler for employment. The dominant view was that employers constituted a barrier because of their negative attitudes, lack of knowledge, and need of support in connection to jobseekers and employees with mental health problems.

\subsubsection{Employers as both barriers and enablers}

Professionals mentioned several barriers related to employers. When the individual on sick- leave had a job to return to, employers were thought to be entering the RTW process too late, and thereby prolonging the sick-leave period (MHS, PC, SIA). When the employee returned after sick-leave, employers were felt to lack knowledge and understanding regarding the individual's functional limitations. Employers would demand high work ability, and that could lead to an illness relapse (OHS, PES). Disputes between the employer and employee were also mentioned as creating barriers that made it difficult for the employee on sick-leave to return to the same workplace (OHS).

Finding employment for individuals with mental health problems was described as a major challenge, and it was estimated that three-quarters of contacted employers declined to hire. Various explanations were given: no need to hire, company reorganization, and lack of available mentors (CA). In that context, understanding that employers had different perspectives and other employees to consider was thought to be important (IPS, OHS).

In contrast to these negative impressions, employers were described as key enablers for successful employment. SIA professionals said that most employers want their employees to return after sick-leave. They were felt to be genuinely caring for their employee's wellbeing (MHC) and trying to make adaptations according to the employee's needs (OHS). Employers were generally satisfied with their employees and acquired knowledge of the employee's work ability before employment (CA).

Small- and medium-sized firm employers were perceived as enablers and much more interested in hiring (CA, PES). Employers in larger companies had less flexibility to hire a specific individual because they had to follow prescribed recruitment processes (PES). Employers in smaller companies posed challenges by not always following the work task agreement or adaptations. They often needed a flexible employee to cover areas other than those agreed upon, even though the employer knew about the employee's functional limitations (PES). Employers in information technology businesses and telemarketing were described as enablers with high tolerance for individuals' variability in function (PES). Organizations such as charities were also seen as enablers with considerable experience with individuals with mental health problems (CA). Nevertheless, the employment specialists (IPS) saw a risk in employers with who had too many individuals with the same problems:

"Some companies are great at accepting and helping people who are excluded, and of course it's great that they help. But suddenly, you have 
a whole working group of people who feel bad in different ways."

\subsubsection{Employers in need of knowledge and support}

In general, professionals described employers as lacking knowledge and needing support in regard to mental health problems. The lack of knowledge could lead to misunderstandings and fear of individuals with mental health problems (IPS, MHS, PC, SIA). The RTW process was improved among employers who had previous experience with mental health problems (IPS). Internship placements for individuals with mental health problems could be such an approach that allows employers the chance to see the person behind the diagnosis without any obligation of hiring. A CA professional expressed this:

"What I mean is that then it is not just 'an Asperger', 'a bipolar', 'a post-traumatic stress syndrome'. It will be 'Carl', and you get over many of the fears when there's a person sitting there, who you have coffee with, and get to know."

Additionally, knowledge concerning the employer's work responsibility according to the Work Environment Act, and thus their responsibilities for rehabilitation and adaptations according to the individual's needs was also perceived as deficient (OHS, PC, PES, SIA).

\subsubsection{Financial situation impacts employer actions}

Professionals thought that employers had a strong interest in productivity and profits (CA, IPS, PES, SIA). Employers could be divided into two groups-those who saw a gain with wage-subsidies for the hiring company and those who were socially committed and desired to help (CA, IPS, PES). Employer financial concerns were described in a variety of ways. When the individual was employed, employers could have a hidden agenda related to the inability to cover sick-leave and productivity loss, and consequently would attempt to dismiss the employee when hospital care was received (MHS). Professionals working with unemployed individuals on sick-leave described discussion of the wage-subsidy before the potential employee started to work (CA, IPS, PES SIA). The wage-subsidy was therefore seen as a motive for hiring, and the employment disappeared without that benefit (PES). Nonetheless, even though employers were financially compensated for functional limitations, they might still expect a fully productive individual. Employers were positive about paying only for the hours the individuals actually worked, and the rest needed to be compensated by the wage-subsidy (CA). An added perception was that employers did not want to hire a person with mental health problems when they could hire a healthy person. Offering high-risk-protection was a way to overcome employer concern about frequent sick-leave periods. This compensation is paid by SIA, supported by a medical certificate, and can be given to employers if an employee is frequently away on sick-leave (PES).

\section{Discussion}

In accordance with the explorative aims associated with mental health literacy, professionals hold a position of power through their professional position and the roles and regulations of their respective authorities or organizations. Their knowledge was simultaneously viewed as both sufficient and insufficient, while collaboration was largely deficient and caused service and time gaps between different phases and actors in the RTW process. The perception of an individual's ability to work was predominantly positive. Nonetheless, functional limitations were frequently a focus and wage-subsidies were regularly used. Contact with employers was mostly perceived in negative terms, and employers were experienced as having inadequate knowledge, and needing support and financial incentives to facilitate employment. Against this background, we believe professionals and the rules set up by their authorities or organizations influence the approach to employers, and signal disbelief in the work ability of individuals with mental health problems. Since ultimately an employer's goals concern productivity (Engstrom \& Janson, 2007; Gustafsson, 2014), it can be argued that the individual's ability is of most interest to employers, rather than the professionals' focus on functional limitations and diagnosis. This is consistent with the clinical recovery approach where symptoms need to be reduced before an individual is placed in employment (Davidson et al., 2005). Vocational rehabilitation professionals would benefit from understanding the power they possess, the signals they send in the RTW process, and how these can influence and affect employers.

The professional's knowledge and organisational activities within their role (e.g. medical knowledge, participating in status meetings) are a source of 
power. Professionals can enable the RTW process and work as a collaborative, expert team towards the goal of employment when these pieces function. However, a lack of knowledge or collaboration can lead to incorrect or delayed decisions and generate frustration among other actors involved in the process (Porter, Lexén, Johanson, \& Bejerholm, 2018). SIA was the authority experienced most frequently as lacking knowledge. This is a paradox since they are responsible for sick-leave eligibility decisions and calling for status meetings, and yet were not equipped with knowledge that promotes mental health recovery.

Collaboration is viewed as an essential aspect of the RTW process. Such collaboration was surprisingly lacking, and SIA handling officers did not always attend status meetings. To enable collaboration and an integrated service, effective communication is essential (OECD, 2013). Communication is shown to be problematic in the TVR approach since it includes a variety of authorities and organizations that follow different regulations (Audhoe, Nieuwenhuijsen, Hoving, Sluiter, \& Frings-Dresen, 2018; Bejerholm, Larsson, \& Hofgren, 2011; Ekberg, Eklund, \& Hensing, 2015). While this may explain our results to some degree, this should not be used as a justification. The common goal for all those involved in the RTW process should be to make each individual RTW process as effective as possible. A lack of collaboration introduces a barrier for a successful process, and the individual ends up trapped between different organizations (Lexén, Emmelin, \& Bejerholm, 2016; Porter, Lexén, Johanson, \& Bejerholm, 2018). A relevant question is whether the deficient knowledge regarding mental health problems seen in SIA is the root cause of the lack of collaboration. Deficient knowledge might lead to a lack of understanding of the importance of all actors being involved in the process. Alternatively, other reasons such as heavy work load and political targets and decisions may exist and should be explored further.

The results of this study indicate that knowledge and collaboration among professionals can affect how they view and believe in the individual's work ability. That an individual is believed to be able to work despite having mental health problems is reassuring. Nonetheless, wage-subsidies and internship are viewed as necessary and are used extensively to enable employment and compensate for functional limitations. These reinforce the clinical recovery approach where reduction of symptoms is the focus
(Davidson et al., 2005). Since wage-subsidies are so frequently used, one can question whether there is a genuine belief in the individual's ability to work. This approach might instead signal scepticism since wagesubsidies are recurrently used and discussed with employers even before the individuals have tried out the specific work tasks (Lexén, Emmelin, Hansson, \& Bejerholm, unpublished data). Previous research supports our finding that shows professionals can hold negative attitudes towards individuals with mental health problems and their prospects of work (Alonso et al., 2009; Brohan et al., 2012; Lammerts et al., 2016). These attitudes may be an explanation for the frequent use of wage-subsidies. Professionals need to shift away from this point-of-view (i.e., focus on an individual's deficit) toward seeing the potential of the person as a working individual as stated by Slade (2009). This does not mean that mental health problems should not be addressed in relation to the work task since individuals with such problems can present challenges in the work setting. As Bertilsson et al. (2015) highlighted, professionals perceive individuals with mental health problems as having difficulty with time management and withdrawing from social contexts (Bertilsson et al., 2015). Nevertheless, matched with the right job and the right adaptations, the individual's functional limitations might not be a concern. Professionals have the ability to steer focus away from limitations (as seen in research using the IPS approach) and put the focus on the individual's ability. The employment specialist can be a positive force by believing in the individual's ability to find competitive employment (Areberg, Björkman, \& Bejerholm, 2013; Lexén, Emmelin, \& Bejerholm, 2016; Porter, Lexén, Johanson, \& Bejerholm, 2018). This positive approach not only affects the individuals and the way they perceive themselves (Porter, Lexén, Johanson, \& Bejerholm, 2018), but could also reflect positively on the employer and other professionals, with an optimistic reinforcing effect on the belief in the potential of the individual with mental health problems as a working individual. Even though numerous studies show the positive effect of IPS (Bejerholm et al., 2015; Bejerholm, Larsson, \& Johanson, 2017; Kinoshita et al., 2013; Noel et al., 2018; Porter \& Bejerholm, 2018; Porter, Lexén, Johanson, \& Bejerholm, 2018), the clinical recovery approach still dominates the RTW process in Sweden and places emphasis on health problems instead of work ability.

A professional's position of power, views and beliefs in the individuals work ability can influence 
employer attitudes and knowledge towards individuals with mental health problems in the RTW process. Professionals experienced employers as a key factor in employment, but mostly as creating an additional barrier to employment because of a lack of knowledge and sometimes stigmatized views of mental health problems. Earlier research supports our findings that mental health professionals view employers as lacking knowledge (Lexén et al., unpublished data), and having deficient understanding of the need for adaptations for mental health problems (Bertilsson et al., 2015). Multidimensional reasons for this barrier are likely, but when professionals themselves signal a lack of understanding of mental health problems (such as viewing the individuals as incapable of a real job and focusing on the functional limitations), this has potential to cause hesitation and apprehension among hiring employers (Lexén et al., unpublished data). This study demonstrates the need to support employers. Not offering needed support can also hinder employment (Lexén, Emmelin \& Bejerholm, 2016). Continuing to provide employer support after employment has been achieved increases the likelihood of the employment (Gilbride, Stensrud, Vandergoot \& Golden, 2003).

Disclosure of mental health problems is a dilemma and experienced as having both positive and negative consequences because of strong links to stigma. The majority of professionals were supportive of disclosure to employers as this created an understanding of the client's problems. However, this might again send signals of functional limitations to both the individual and employer. It is noteworthy that individuals can have a different view on this matter and experienced negative consequences of disclosure to employers. For example, an individual might be viewed as not suitable for the job or incompetent since mental health problems remain associated with stigma both among employers and in society (Hamilton et al., 2014).

Individuals with mental health problems are a vulnerable group who would benefit from personcentred support by professionals in the RTW process (Audhoe et al., 2018; Durand et al., 2014; Porter, Lexén, Johanson, \& Bejerholm, 2018). They not only suffer from mental health problems, which can be difficult to understand, but during the RTW process they also encounter professionals with different roles and regulatory frameworks and diverse approaches. Additionally, they encounter employers who may hold negative views of their work capabilities.

\subsection{Implications}

This study provides insight into vocational rehabilitation professionals' mental health literacy, a precondition to achieve improvements in the RTW process. Professionals would benefit from understanding their role and the signals they send to the individuals with mental health problems, other professionals, and employers in the RTW process, where a focus may be on functional limitations. If the focus is switched to ability, a more positive process for individuals and employers would be created. In turn, this could increase the likelihood of a successful outcome.

Further studies should explore the experience of employees with mental health problems in the workplace setting, as this could contribute to increasing the employer's knowledge base.

\subsection{Methodological considerations}

This study followed the Charmaz (Charmaz, 2014) methodological guidelines and the authors took several measures to enhance trustworthiness. When selecting the informants, theoretical sampling was applied to give a broad selection of professionals with different perceptive and experience who are working in the RTW process. This procedure worked well. The seven different settings in which the professionals worked provided diverse and broad interview material. Each interview was transcribed and analysed separately by the authors, and consensus was reached when the codes, categories and sub-categories were agreed to among the authors. Memo-writing was used as an ongoing measure that allowed the authors to reflect on the analysis and the connections between categories and sub-categories (Charmaz, 2014). To further increase credibility, the authors included quotations that aim to give the reader a deeper understanding of informant views. When the analysis was completed, two professionals working in the RTW process from outside of the study sample had the opportunity to give feedback on the results. No changes were made at this stage since they approved of the authors' interpretations. While it could be argued that the professionals and work settings were too diverse, and that each group was too small to draw strong conclusions, this is not the purpose when using grounded theory. Instead, the aim is to develop a conceptual model, include a diverse set of professionals, and view how their interaction in the RTW process. 


\section{Conclusion}

This study provides insights into the mental health literacy of vocational rehabilitation professionals and how this can influence employer attitudes and knowledge in the RTW process. The results show a complex process surrounds an individual in need of the professionals' services, where several different actors from diverse settings with various knowledge and approaches are involved. The regulations of the respective authority or organization of the professional frame the RTW process towards the individual and employers, with the focus on functional limitations. Shifting the focus to the individual's work ability for a specific work task in combination with increasing the mental health literacy among the professionals would benefit clients in the RTW process.

\section{Acknowledgments}

We want to thank all the participants who so generously contributed to this study, as well as the Swedish Social Insurance Agency (Dnr: 0578262014), and the Department of Health Sciences and Mental Health, Activity and Participation at Lund University for funding this research.

\section{Conflict of interest}

The authors declare that they have no conflict of interest.

\section{References}

Alonso, J., Buron, A., Rojas-Farreras, S., De Graaf, R., Haro, J. M., De Girolamo, G., \& Vilagut, G. (2009). Perceived stigma among individuals with common mental disorders. Journal of Affective Disorder, 118(1), 180-186.

Areberg, C., Björkman, T., \& Bejerholm, U. (2013). Experiences of the individual placement and support approach in persons with severe mental illness. Scandinavian Journal of Caring Sciences, 27(3), 589-596.

Audhoe, S. S., Nieuwenhuijsen, K., Hoving, J. L., Sluiter, J. K., \& Frings-Dresen, M. H. (2018). Perspectives of unemployed workers with mental health problems: Barriers to and solutions for return to work. Disability and Rehabilitation, 40(1), 28-34.

Bejerholm, U., \& Areberg, C. (2014). Factors related to the return to work potential in persons with severe mental illness. Scandinavian Journal of Occupational Therapy, 21(4), 277-286.
Bejerholm, U., Areberg, C., Hofgren, C., Sandlund, M., \& Rinaldi, M. (2015). Individual Placement and Support in Sweden-A randomized controlled trial. Nordic Journal of Psychiatry, 69(1), 57-66.

Bejerholm, U., Larsson, L., \& Hofgren, C. (2011). Individual placement and support illustrated in the Swedish welfare system: A case study. Journal of Vocational Rehabilitation, 35(1), 59-72.

Bejerholm, U., Larsson, M. E., \& Johanson, S. (2017). Supported employment adapted for people with affective disorders-A randomized controlled trial. Journal of Affective Disorder, 207, 212-220

Bertilsson, M., Love, J., Ahlborg, G., Jr., \& Hensing, G. (2015). Health care professionals' experience-based understanding of individuals' capacity to work while depressed and anxious. Scandinavian Journal of Occupational Therapy, 22(2), 126136. doi: 10.3109/11038128.2014.985607

Brohan, E., Henderson, C., Wheat, K., Malcolm, E., Clement, S., Barley, E. A., \& Thornicroft, G. (2012). Systematic review of beliefs, behaviours and influencing factors associated with disclosure of a mental health problem in the workplace. BMC Psychiatry, 12, 11. doi: 10.1186/1471-244x-12-11

Burstrom, B., Nylen, L., Clayton, S., \& Whitehead, M. (2011). How equitable is vocational rehabilitation in Sweden? A review of evidence on the implementation of a national policy framework. Disability and Rehabilitation, 33(6), 453-466.

Charmaz, K. (2014). Constructing grounded theory (2nd ed.). London, UK: SAGE.

Charmaz, K. (2017). Special invited paper: Continuities, contradictions, and critical inquiry in Grounded Theory. International Journal of Qualitative Methods, 16(1), 1609406917719350.

Chisholm, D., Sweeny, K., Sheehan, P., Rasmussen, B., Smit, F., Cuijpers, P., \& Saxena, S. (2016). Scaling-up treatment of depression and anxiety: A global return on investment analysis. The Lancet Psychiatry, 3(5), 415-424.

Davidson, L., O'Connell, M. J., Tondora, J., Lawless, M., \& Evans, A. C. (2005). Recovery in serious mental illness: A new wine or just a new bottle? Professional Psychology: Research and Practice, 36(5), 480.

De Vries, G., Hees, H. L., Koeter, M. W., Lagerveld, S. E., \& Schene, A. H. (2014). Perceived impeding factors for return-to-work after long-term sickness absence due to major depressive disorder: A concept mapping approach. Plos One, 9(1), e85038.

Durand, M. -J., Corbière, M., Coutu, M. -F., Reinharz, D., \& Albert, V. (2014). A review of best work-absence management and return-to-work practices for workers with musculoskeletal or common mental disorders. Work, 48(4), 579-589.

Ekberg, K. (2009). Faser i arbetslivsinriktad rehabilitering (Phases in vocational rehabilitation). Socialmedicinsk Tidskrift, 86(3), 210-219.

Ekberg, K., Eklund, M., \& Hensing, G. (2015). återgång i arbete: Processer, bedömningar, åtgärder (Return to work: Processes, assessments and interventions). Studentlitteratur AB.

Engstrom, L. G., \& Janson, S. (2007). Stress-related sickness absence and return to labour market in Sweden. Disability and Rehabilitation, 29(5), 411-416. doi: 10.1080/09638280600835986

Gilbride, D., Stensrud, R., Vandergoot, D., \& Golden, K. (2003). Identification of the characteristics of work environments and employers open to hiring and accommodating people with disabilities. Rehabilitation Counseling Bulletin, 46(3), 130-137. 
Gustafsson, J. (2014). Supported employment i en svensk kontext: förutsättningar när personer med funktionsnedsättning når, får och behåller ett arbete. (Supported employment in a Swedish context: Conditions when people with disabilities reach, receive and retain a job.) Örebro universitet.

Hamilton, S., Lewis-Holmes, E., Pinfold, V., Henderson, C., Rose, D., \& Thornicroft, G. (2014). Discrimination against people with a mental health diagnosis: Qualitative analysis of reported experiences. Journal of Mental Health, 23(2), 88-93. doi: 10.3109/09638237.2014.880408

Johanson, S., Markström, U., \& Bejerholm, U. (2017). Enabling the return-to-work process among people with affective disorders: A multiple-case study. Scandinavian Journal of Occupational Therapy, 1-14.

Jorm, A. F., Korten, A., Jacomb, P., Christensen, H., Rodgers, B., \& Pollitt, P. (1997). Mental health literacy a survey of the public's ability to recognise mental disorders and their beliefs about the effectiveness of treatment. Medical Journal of Austrailia, 166(4), 182-186.

Joyce, S., Modini, M., Christensen, H., Mykletun, A., Bryant, R., Mitchell, P. B., \& Harvey, S. B. (2016). Workplace interventions for common mental disorders: A systematic meta-review. Psychological Medicine, 46(4), 683-697. doi: 10.1017/S0033291715002408

Ju, S., Roberts, E., \& Zhang, D. (2013). Employer attitudes toward workers with disabilities: A review of research in the past decade. Journal of Vocational Rehabilitation, 38(2), 113-123.

Kinoshita, Y., Furukawa, T. A., Kinoshita, K., Honyashiki, M., Omori, I. M., Marshall, M., \& Kingdon, D. (2013). Supported employment for adults with severe mental illness. Cochrane Database of Systematic Review, (9), Cd008297. doi: 10.1002/14651858.CD008297.pub2

Kirsh, B., Stergiou-Kita, M., Gewurtz, R., Dawson, D., Krupa, T., Lysaght, R., \& Shaw, L. (2009). From margins to mainstream: What do we know about work integration for persons with brain injury, mental illness and intellectual disability? Work, 32(4), 391-405.

Lammerts, L., Schaafsma, F. G., Bonefaas-Groenewoud, K., van Mechelen, W., \& Anema, J. R. (2016). Effectiveness of a return-to-work program for workers without an employment contract, sick-listed due to common mental disorders. Scandinavian Journal of Work Environment \& Health, 42(6), 469-480. doi: 10.5271/sjweh.3588

Lexén, A., Emmelin, M., \& Bejerholm, U. (2016). Individual Placement and Support is the keyhole: Employer experiences of supporting persons with mental illness. Journal of Vocational Rehabilitation, 44(2), 135-147.

Marcus, M., Yasamy, M. T., van Ommeren, M., Chisholm, D., \& Saxena, S. (2012). Depression: A global public health concern. WHO Department of Mental Health and Substance Abuse, 1, 6-8.

Modini, M., Joyce, S., Mykletun, A., Christensen, H., Bryant, R. A., Mitchell, P. B., \& Harvey, S. B. (2016). The mental health benefits of employment: Results of a systematic meta-review. Australasian Psychiatry, 24(4), 331-336.
Moll, S. E. (2014). The web of silence: A qualitative case study of early intervention and support for healthcare workers with mental ill-health. BMC Public Health, 14(1), 138.

Noel, V. A., Oulvey, E., Drake, R. E., Bond, G. R., CarpenterSong, E. A., \& DeAtley, B. (2018). A preliminary evaluation of individual placement and support for youth with developmental and psychiatric disabilities. Journal of Vocational Rehabilitation, 48(2), 249-255.

OECD. (2013). Mental Health and Work. OECD Publishing Sweden.

Porter, S., \& Bejerholm, U. (2018). The effect of individual enabling and support on empowerment and depression severity in persons with affective disorders: Outcome of a randomized control trial. Nordic Journal of Psychiatry, 30, 1-9.

Porter, S., Lexén, A., Johanson S., \& Bejerholm U. (2018). Critical factors for the return-to-work process among people with affective disorders: Voices from two vocational approaches. Work, 60(2).

Reme, S. E., Grasdal, A. L., Løvvik, C., Lie, S. A., \& Øverland, S. (2015). Work-focused cognitive-behavioural therapy and individual job support to increase work participation in common mental disorders: A randomised controlled multicentre trial. Occupational and Environmental Medicine, 72(10), 745-752.

Saha, S., Bejerholm, U., Gerdtham, U. G., \& Jarl, J. (2018). Costeffectiveness of supported employment adapted for people with affective disorders. Nordic Journal of Psychiatry, 1-4. doi: 10.1080/08039488.2017.1422801

Slade, M. (2009). Personal recovery and mental illness: A guide for mental health professionals. Cambridge University Press, pp. $77-124$.

Slade, M. (2010). Mental illness and well-being: The central importance of positive psychology and recovery approaches. BMC Health Services Research, 10, 26. doi: 10.1186/14726963-10-26

SOU. (2011). Rehabiliterinsrådets slutbetänkande (Rehabilitation Council's final report). Stockholm: Elanders Sverige AB. Statens Offentliga Utredningar, 15, pp. 1-223.

Ståhl, C., Svensson, T., \& Ekberg, K. (2011). From cooperation to conflict? Swedish rehabilitation professionals' experiences of interorganizational cooperation. Journal of Occupational Rehabilitation, 21(3), 441-448.

Topor, A., \& Ljungberg, A. (2016). "Everything is so relaxed and personal"-The construction of helpful relationships in individual placement and support. American Journal of Psychiatric Rehabilitation, 19(4), 275-293.

Williams, A. E., Fossey, E., Corbiere, M., Paluch, T., \& Harvey, C. (2016). Work participation for people with severe mental illnesses: An integrative review of factors impacting job tenure. Australian Occupational Therapy Journal, 63(2), 65-85. doi: 10.1111/1440-1630.12237 